\title{
Vibration Characteristics of Force Signal for Single Diamond Grit Scratching Process
}

\author{
Haiyong $\mathrm{Wu}^{1,2,3,4}$ \\ ${ }^{1}$ College of Mechanical Engineering, Zhangzhou Institute of Technology, Zhangzhou, 363000, Fujian Province, \\ China. E-mail: haiyongwu@126.com \\ ${ }^{2}$ Post-Doctoral Research Center, Fujian Longxi Bearing (Group) Corp., LTD., Zhangzhou, 363000, Fujian Pro- \\ vince, China. \\ ${ }^{3}$ College of Mechanical and Automation Engineering, Huaqiao University, Xiamen, 361021, Fujian Province, \\ China. \\ ${ }^{4}$ College of Mechanical Engineering and Automation, Fuzhou University, Fuzhou, 350116, Fujian Province, China.
}

Scratching force is a significant factor to evaluate the characteristics of single diamond grit scratching process. In this paper, experimental study was carried out to investigate the vibration characteristics of force signals during the scratching process. A precise multicomponent dynamometer is employed in the force measurement during a single diamond grit scratching on pure copper. The frequencies of the vibration section of force signals with different scratching parameters are calculated and analyzed. The influence of force signal vibration on the measuring accuracy of dynamometer is systematically analyzed further. The results show that higher scratching speed and larger scratching depth lead to larger vibration amplitudes of the force signals. Strong impact on the quartz piezoelectric crystal of dynamometer, which is produced indirectly by single diamond grit scratching process, leads to the vibration of scratching force signal. The first semi-sinusoidal force signal is the actual scratching force. The vibration of the scratching force signal has little effect on the measuring accuracy of the dynamometer.

Keywords: Single Diamond Grit, Scratching, Force Signal, Signal Vibration

\section{Introduction}

Single diamond grit scratching process is an effective approach to investigate the complex situation of diamond wheel grinding process. The influence of grits and chips on the grinding arc area could be avoided with single diamond grit scratching process $[1,2]$. Thus, it is widely used to realize the workpiece material removal mechanism and wear characteristics durint the machining process [3].

Scratching force is considered as one of the most essential parameter for the scratching process. Force measurement in the scratching process is commonly carried out by piezoelectric crystal dynamometers [4]. The scratching force signals in the post studies are almost extracted and presented as a value [5]. However, the scratching force signal varies dynamically with the workpiece material removal volume.

The scratching normal force $F n$ and tangential force Ft present to be a semi-sinusoidal variation during the single diamond grit scratching process. Scratching experiments with a pendulum setup were carried out just with a low scratching speed $(0.05 \mathrm{~m} / \mathrm{s})$ [6]. The scratching force signals with higher speeds were measured and exhibited to be vibration [7]. However, the reasons why the scratching force signals appear to be vibration were not discussed further in the post studies. To date, there is no clear understanding on the vibration characteristics of single diamond grit scratching force signals.

This paper attempts to present and illustrate the vibration characteristics of force signals during the single dianmod grit scratching process. The force signals are measured by a precise piezoelectric crystal dynamometer during a single diamond grit scratching on pure copper. The influences of force signal vibration on the measuring accuracy of dynamometer are analyzed systematically to investigate the vibration characteristics of scratching force signals.

\section{Experimental procedure}

The scratching experiments were carried out on a precision grinding machine (Blohm Planomat HP408) as shown in Fig. 1. A single diamond grit, which was a Rockwell hardness indenter with $90^{\circ}$ cone apex angle, was mounted to a dummy wheel with threaded connection. Pure copper, which has excellent plasticity, was selected as the workpiece material in the scratching experiments. The pure copper disc was stuck onto the dynamometer directly. The dynamometer was mounted on a clamp which was magnetically adsorbed on the machine table. The pure copper was 
precision machined with flatness was $1 \mu \mathrm{m}$ and $\mathrm{Ra}=$ $0.5 \mu \mathrm{m}$. The scratches on pure copper separated from each other.
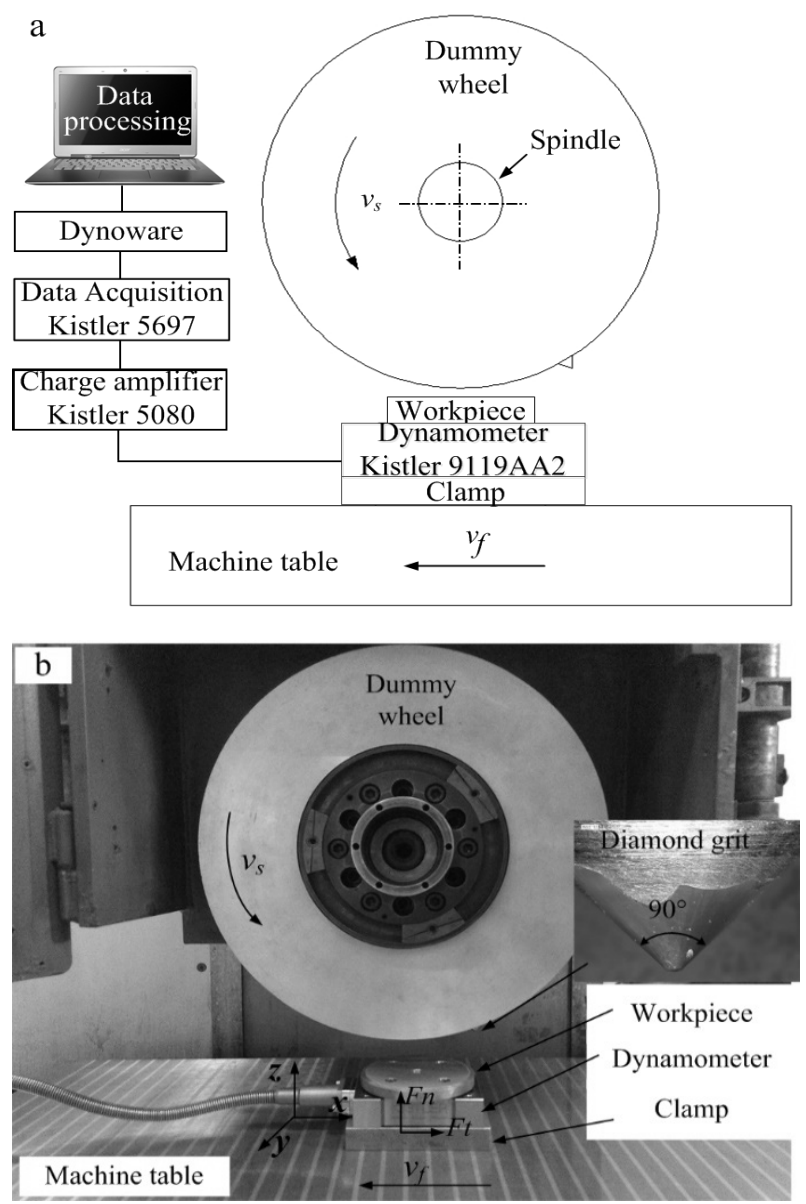

Fig. 1 The single diamond scratching experimental setup, schematic diagram (a) and actual setup diagram (b).

The force signals were measured by multicomponent dynamometer Kistler 9119AA2. The scratching speeds are $0.5-40 \mathrm{~m} / \mathrm{s}$ and scratching depths are $10-40$ $\mu \mathrm{m}$. The dynamometer is precisely designed with high sensitivity $(-26 \mathrm{pC} / \mathrm{N},-13 \mathrm{pC} / \mathrm{N},-26 \mathrm{pC} / \mathrm{N}$ in $x, y$, z dimensions respectively) and high natural frequency $(4.3 \mathrm{kHz}, 4.6 \mathrm{kHz}, 4.4 \mathrm{kHz}$ in $x, y$, z dimensions respectively), and it can be employed for microcutting force measurement in precision and ultra-precision machining. The dynamometer was in connected with Kistler charge amplifier 5080. The force signals data was acquired by Kistler 5697 and analyzed by Dynoware software. The sampling frequency was 91 $\mathrm{kHz}$. Meanwhile, the influence of a steel ball free dropping and a steel bar striking directly on the dynamometer were tested further to investigate the vibration characteristics of force signals.

\section{Results}

\subsection{Scratching force signals}

A typical scratch on the pure copper disc and its corresponding normal force $F n$ and tangential force $F t$ obtained during the scratching process are shown in Fig. 2. The scratch is produced at a relatively low scratching speed $v_{s}=0.5 \mathrm{~m} / \mathrm{s}$ and scratching depth $a_{p}=20$ $\mu \mathrm{m}$. The normal force $F n$ and tangential force Ft vary with the scratching depth and display a semi-sinusoidal variation during the scratching process. Similar scratch traces and force profiles were also observed by Wang [8] and Subhash [9]. However, these experiments were all carried out with a low scratching speed.

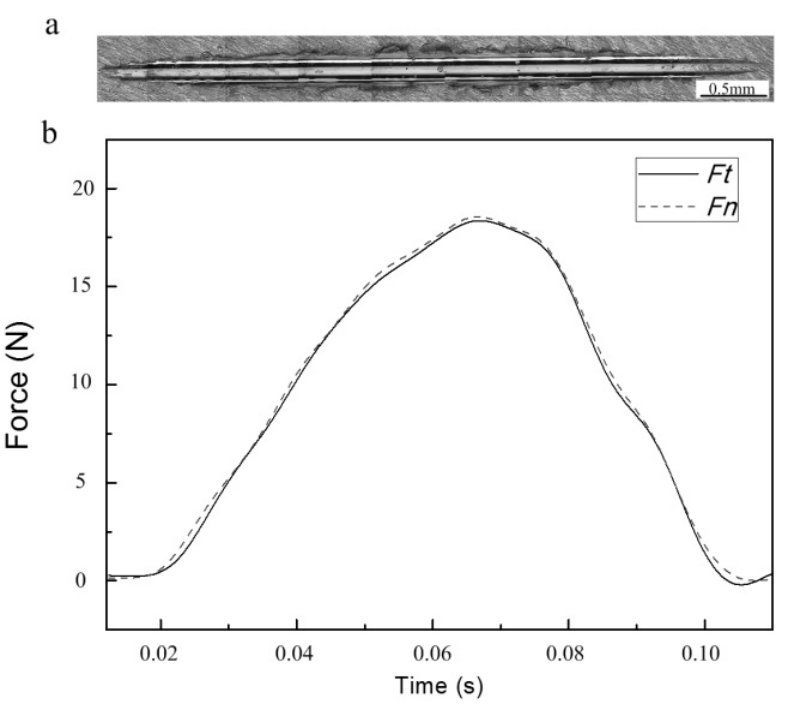

Fig. 2 A typical scratch on pure copper (a) and its normal force Fn and tangential force Ft (b) with $v_{s}=0.5 \mathrm{~m} / \mathrm{s}$ and $a_{p}$

$$
=20 \mu \mathrm{m} \text {. }
$$

Experiments with higher scratching speeds and larger scratching depths were carried out to investigate the influence of different scratching parameters on the scratching force signals. The scratching force signals, which scratching depth and scratching speed are 20 $\mu \mathrm{m}$ and $2.5-20 \mathrm{~m} / \mathrm{s}$ respectively, are shown in Fig. 3 . It could be observed that both the tangential force $\mathrm{Ft}$ (Fig. 3a) and normal force Fn (Fig. 3b) display the same evolution, and present to be vibration at the tail of the first peak of the force signal curves. Higher scratching speeds result in larger vibration amplitude of the scratching force signals. The force signals attenuate continuously after the initial vibration point. They are obviously different from the force signals with a low scratching speed (Fig. 2).

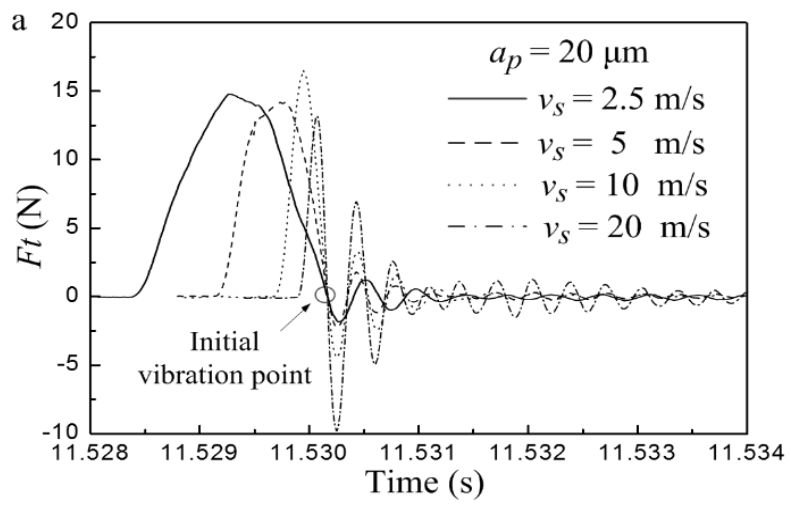




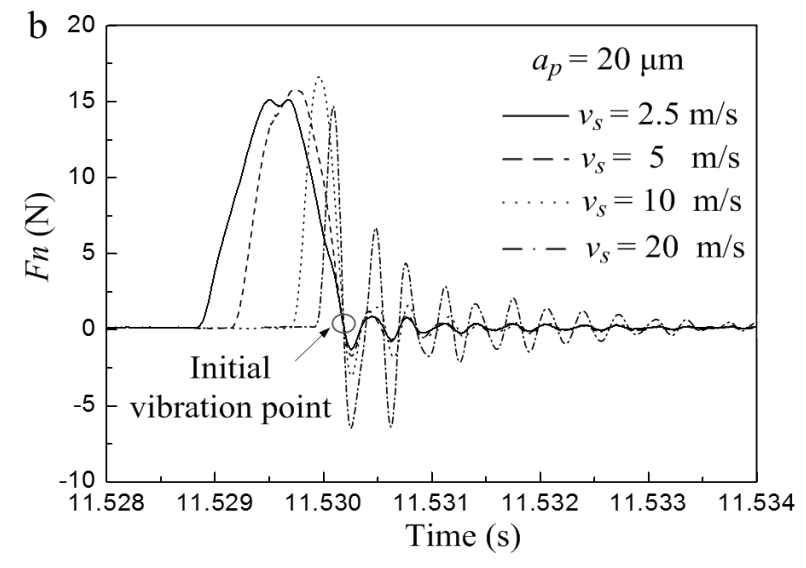

Fig. 3 The tangential force (a) and the normal force (b) with $a_{p}=20 \mu \mathrm{m}$ and $v_{s}=2.5-20 \mathrm{~m} / \mathrm{s}$.

The scratching force signals, which scratching speed and scratching depth are $20 \mathrm{~m} / \mathrm{s}$ and $10-40 \mu \mathrm{m}$ respectively, are shown in Fig. 4. The tangential force Ft (Fig. 4a) and normal force Fn (Fig. 4b) exhibit to be vibration after the first peak of the scratching force signals. The vibration characteristics of force signals are similar to the above Fig. 3. The vibration amplitude becomes larger with the increasing of scratching depth. The above results show that the scratching force signals appear the same vibration tendency with different higher scratching speeds and scratching depths.
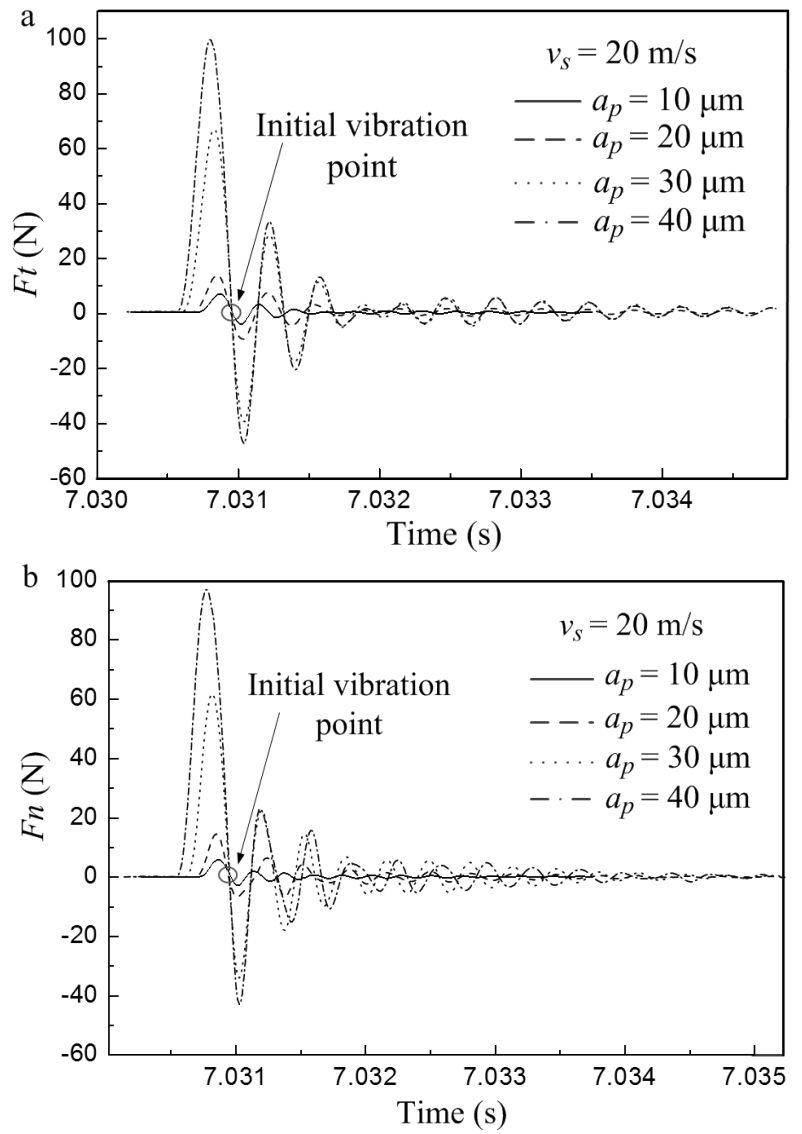

Fig. 4 The tangential force $\mathrm{Ft}(\mathrm{a})$ and the normal force $\mathrm{Fn}$ (b) with $v_{s}=20 \mathrm{~m} / \mathrm{s}$ and $a_{p}=10-40 \mu \mathrm{m}$.

\subsection{Impacting force signals}

In order to compare with the vibration characteristics of the scratching force signals, two impacting force experiments were carried out as shown in Fig. 5. The force signal of a steel ball free dropping directly on the dynamometer one-time with a certain height (about $0.5 \mathrm{~m}$ ) is shown in Fig. 5a. It can be observed that the amplitude of the first peak of the force signal is larger than that of other vibration signals. Meanwhile, the vibration of the force signal attenuates continuously for a rather long progress.

The force signal of a steel bar striking directly on the dynamometer is shown in Fig. 5b. It can be observed that the variation of the force signal is similar with Fig. 5a. The force signals of a steel ball free dropping and a steel bar striking are both impacting forces for the dynamometer, and they are similar to the force signals of single diamond grit scratching process (Fig. 3 and Fig. 4). Therefore, it could be speculated that the vibration of scratching force signals are most probably produced by the direct impact of the single diamond grit scratching process.
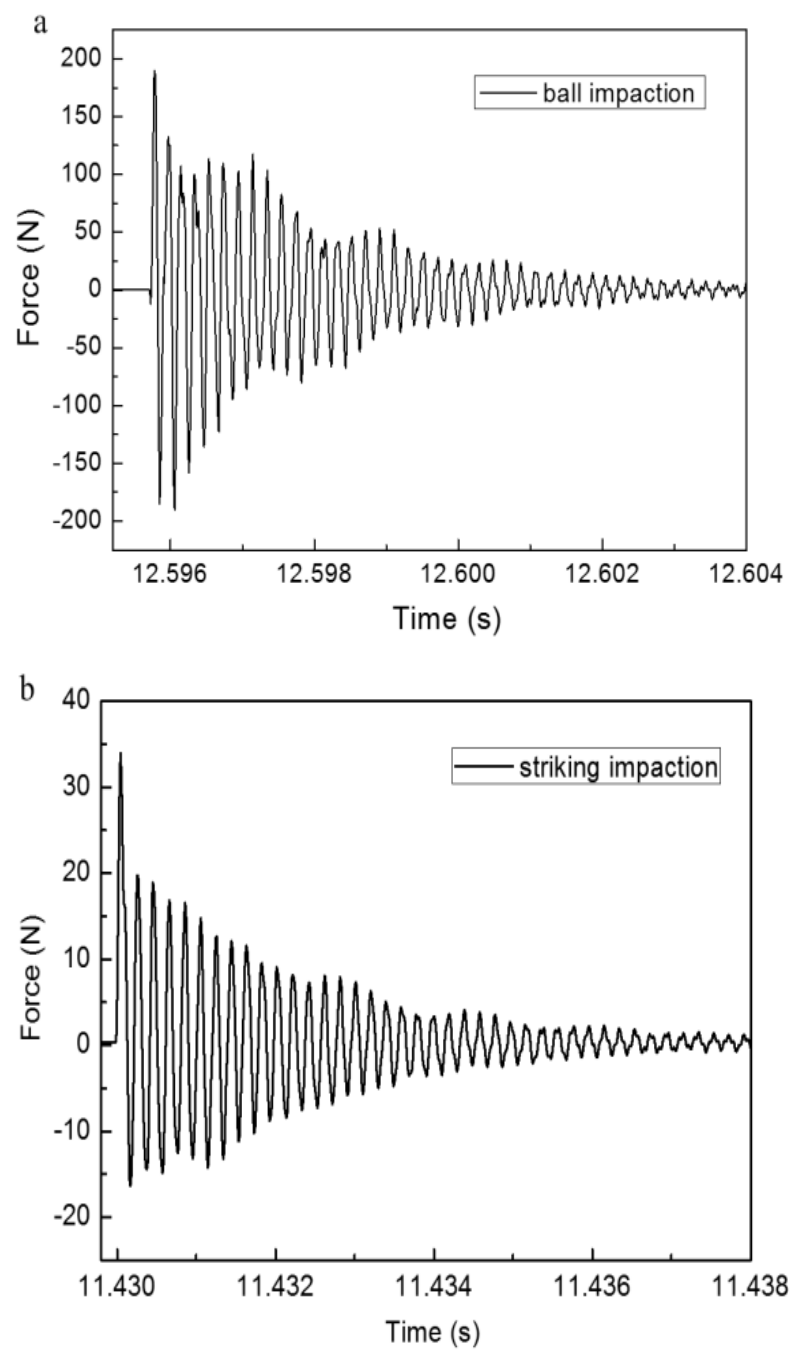

Fig. 5 The force signals of a steel ball free dropping (a) and a steel bar striking (b) directly on the dynamometer. 


\section{Discussion}

\subsection{Frequency spectrum analysis}

The vibration section of the scratching force signals with $a_{p}=40 \mu \mathrm{m}$ and $v_{s}=20 \mathrm{~m} / \mathrm{s}$ are spectral analyzed with fast Fourier transform as shown in Fig. 6. It can be observed that there is a peak in the spectral figure. The amplitude reaches the peak when the measurement system frequency is $3092 \mathrm{~Hz}$.

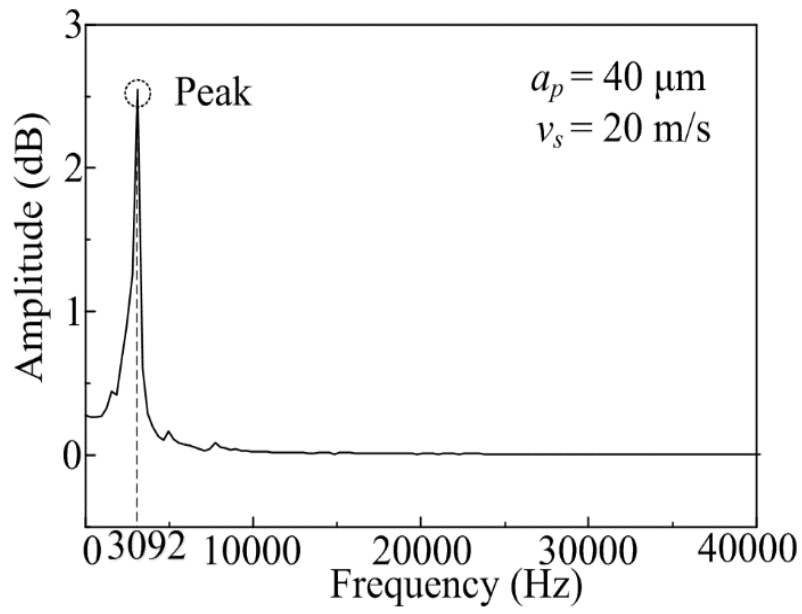

Fig. 6 The spectral analyses of the scratching force vibration section.

The peak frequencies of the vibration section for the normal forces signals with different scratching parameters are shown in Fig. 7. It is obviously that the peak frequencies of the vibration signals with different scratching parameters are almost within the range of 2950-3200 Hz. The frequency of the measurement system can be calculated as [9]:

$$
f=\frac{1}{2 \pi} \sqrt{\frac{k}{m}}[H z]
$$

Where the $k$ is the stiffness of the measurement system, $m$ is the weight of the measurement system including the workpiece material $(1.38 \mathrm{~kg})$ and the dynamometer $(1.35 \mathrm{~kg})$. According to the specification of the Kistler 9119AA2 dynamometer, the natural frequency without additional mass of the three dimensions $x, y$, z are $4.3 \mathrm{kHz}, 4.6 \mathrm{kHz}$ and $4.4 \mathrm{kHz}$ respectively. The stiffness $k$ of the dynamometer can be calculated $[8,10]$. Therefore, the frequency of the measurement system can be calculated as about $3094 \mathrm{~Hz}$. The calculated frequency is lower than the natural frequency of the dynamometer. However, it is just in the range of the peak frequency of the vibration signals $(2950-3200 \mathrm{~Hz})$, and it is prone to cause resonance.

The analysis above shows that the vibration of scratching force signal is closely related with the strong scratching impact of the diamond grit. High precise quartz piezoelectric crystal, which is shown in Fig. 8, is employed as the core sensor sensitive element of the dynamometer $[9,11]$. The quartz crystal is hexagonal cone as shown in Fig. 8a. A part of the quartz crystal (Fig. 8b) is machined to fabricate dynamometer, and extreme thin precise quartz crystal plate (Fig. $8 \mathrm{c}$ ) is employed in the measurement of dynamometer by utilizing the piezoelectric effect. The strong impact of single diamond scratching process leads to the selfsustained vibration of the quartz crystal plate. Hence, the output force signals appear to vibration.
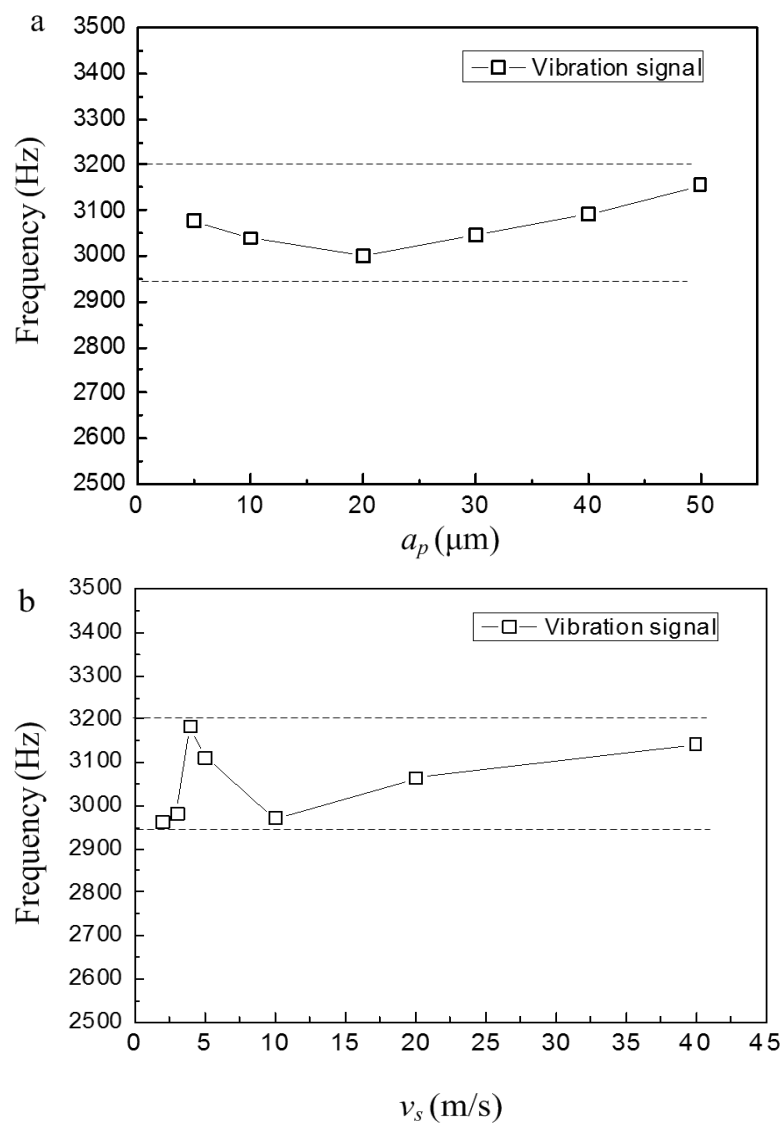

Fig. 7 The peak frequency of the vibration section of normal force signals with (a): $v_{s}=20 \mathrm{~m} / \mathrm{s}, a_{p}=5-50 \mu \mathrm{m}$, and (b): $a_{p}=20 \mu \mathrm{m}, v_{s}=2-40 \mathrm{~m} / \mathrm{s}$.
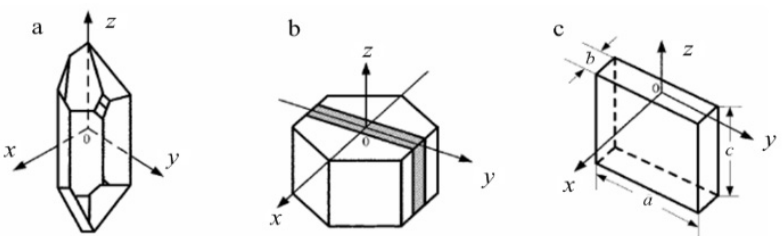

Fig. 8 Quartr piezoelectric crystal is the measurement core of the dynamometer. (a) quartz. crystal structure, (b) a part of the quartz. crystal, (c) the quartz. crystal plate employed in dynamometer measurement.

\subsection{Actual Scratching Force}

Similar vibration situation of force signals was also observed with Kistler 9257B dynamometer during the process of end-milling AISI H13 steel [11]. However, the vibration characteristics of milling force signals were not investigated further, and the first peak of the signals are regarded as the final force value. 


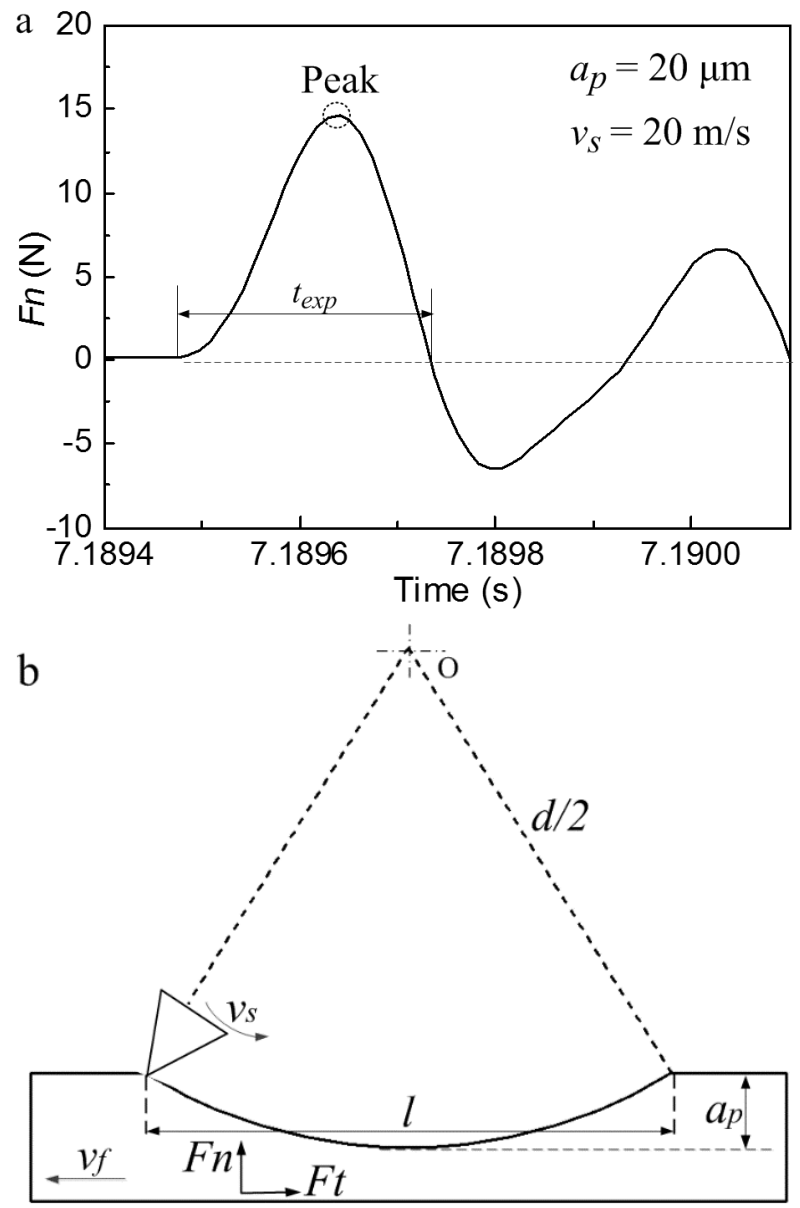

Fig. 9 A single diamond grit scratching normal force (a) and the scratching model (b).

It is necessary to confirm which part of the vibration force signal is the actual scratching force. A typical single diamond grit scratching normal force $F n$ and the scratching model are shown in Fig. 9. The time of the first semi-sinusoid for the experimental normal force signal $t_{\text {exp }}$ (Fig. 9a) is compared with the theoretical calculation time $t_{\text {cal }}$ (Fig. 9b). The arc length of a single scratch $/$ could be calculated by [12]:

$$
l=2 \sqrt{a_{p} d}[m m]
$$

The $d$, which is the equivalent diameter of the scratching wheel, is the sum of the diameter of dummy wheel $(360 \mathrm{~mm})$ and two times of the length of diamond indenter $(10 \mathrm{~mm})$. Therefore, the theoretical scratching time $t_{\text {cal }}$ of a single scratch can be calculated as [13]:

$$
t_{c a l}=\frac{l}{v_{s}}[s]
$$

The error $\Delta \varphi_{\text {time }}$ of the experiment time and calculation time can be denoted as:

$$
\Delta \varphi_{\text {time }}=\frac{\left|t_{\text {exp }}-t_{c a l}\right|}{t_{c a l}} \times 100 \%[-],
$$

The comparison of the two types of scratching time with various scratching parameters is shown in Fig. 10. It can be observed that the variation trends of the experimental time and the calculation time are relatively coherent, and their values are close to each other. The errors of experiment time and calculation time are rather small from $0.25 \%$ to $8.11 \%$. It demonstrated that the first semi-sinusoidal force signal is the actual scratching force. The force signal vibration, which is principally produced by the scratching impact on the quartz crystal plate of the dynamometer, has little influence on the measuring accuracy of the dynamometer.
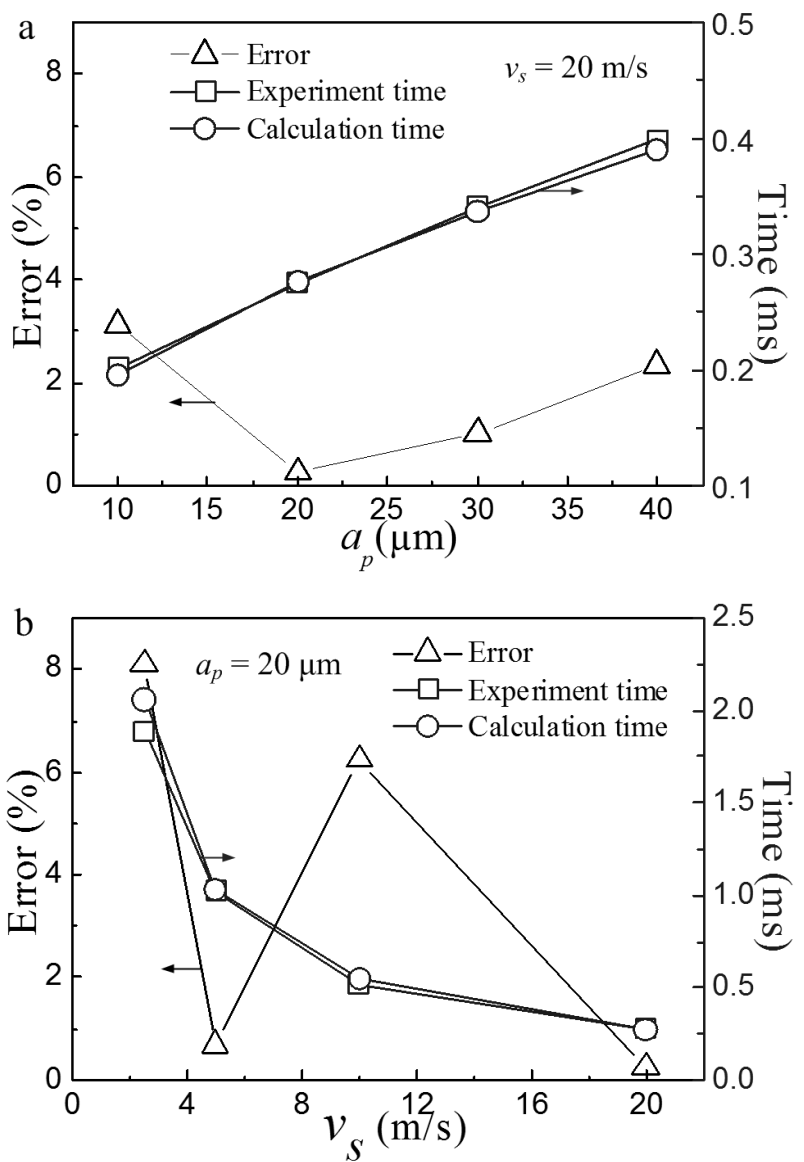

Fig. 10 The time and error of the first peak of the force signals compared with the theoretical calculating value and the experimental value with (a) $v_{s}=20 \mathrm{~m} / \mathrm{s}, a_{p}=1040 \mu \mathrm{m}$; and (b) $a_{p}=20 \mu \mathrm{m}, v_{s}=2.5-20 \mathrm{~m} / \mathrm{s}$.

\section{Conclusions}

In this present work, the vibration characteristics of force signals during single diamond grit scratching on copper are investigated systematically. The main conclusions can be summarized as follows:

The vibration of scratching force signal is strongly affected by the actual scratching condition. A certain degree of resonance would be produced by the force measurement system and experimental scratching conditions. Higher scratching speed and larger scratching depth lead to larger vibration amplitude of the 
scratching force signals.

The force signal vibration depends on the intensity of the impact on the quartz piezoelectric crystal of dynamometer. Strong impact produced indirectly by the single diamond grit scratching process, results in the self-sustained vibration of the quartz crystal plate and the vibration of scratching force signal. The single diamond grit scratching on the workpiece with a lower speed produces a weark impact on the dynamometer, and its force vibration is not obvious.

The first semi-sinusoidal force signal is the actual scratching force, and the first peak value of the scratching force signal can be regarded as the actual force value. The vibration of the scratching force signal has little effect on the measuring accuracy of the dynamometer.

\section{Acknowledgement}

The author would like to acknowledge the support of National Natural Science Foundation of China (Grant No. 51805175), Natural Science Foundation of Fujian Province (Grant No. 2018J05146), China Postdoctoral Science Foundation (Grant No. 2019M652231), Fund of the Institute of Manufacturing Engineering of Huaqiao University (Grant No. 2018IME-001) and Foundation of Doctoral Research Initiation of Zhangzhou Institute of Technology (Grant No. $Z Z Y B 2001)$.

\section{References}

[1] KUNDRAK, J., FEDRORENKO, D.O., FEDOROVICH, V.A., FEDORENKO, E.Y., OSTROVERKH, E.V. (2019) Porous diamond grinding wheels on ceramic binders: Design and manufacturing. In: Manufacturing Tecnoogy, Vol. 19, No. 3, pp. 446-454. Elsevier. Netherlands. ISSN 1213-2489.

[2] KUNDRAK, J., FEDOROVICH, V., MARKOPOULOS, A.P., PYZHOV, I., KRYUKOVA, N. (2014). Improvements of the dressing process of super abrasive diamond grinding wheels. In: Manufacturing Technology, Vol. 14, No.4, pp. 545-554. Elsevier. Netherlands. ISSN 1213-2489.

[3] GRABCHENKO, A., FEDOROVICH, V., PYZHOV, I., KUNDRAK, J. (2014). 3D simulation of vibrating diamond grinding. In: Manufacturing Technology, Vol. 14, No.2, pp. 153-160. Elsevier. Netherlands. ISSN 1213-2489.

[4] KUNDRAK, J., MARKOPOULOS, A.P., MAKKAI, T., DESZPOTH, I., NAGY, A. (2018). Analysis of the effect of feed on chip size ratio and cutting forces in face milling for various cutting speeds. In: Manufacturing Technology, Vol. 18, No.3, pp. 431-438. Elsevier. Netherlands. ISSN 1213-2489.

[5] KUNDRAK, J., GYANI, K., FELHO, C., DESZPOTH, I. (2017). The effect of the shape of chip cross section on cutting force and roughness when increasing feed in face milling. In: Manufacturing Technology, Vol. 17, No.3, pp. 335342. Elsevier. Netherlands. ISSN 1213-2489.

[6] SUBHASH, G., W, Z. (2002) Investigation of the overall friction coefficient in single-pass scratch test. In: Wear, Vol. 252, No.1, pp. 123134. Elsevier. Netherlands. ISSN 0043-1648.

[7] WU, H., HUANG, H., JIANG, F., XU, X. (2016). Mechanical wear of different crystallographic orientations for single abrasive diamond scratching on Ta12W. In: International Journal of Refractory Metals and Hard Materials, Vol. 54, pp. 260-269. Elsevier. Netherlands. ISSN 0263-4368.

[8] WANG, H., SUBHASH, G., CHANDRA, A. (2001). Characteristics of single-grit rotating scratch with a conical tool on pure titanium. In: Wear, Vol. 249, No.7, pp. 566-581. Elsevier. Netherlands. ISSN 0043-1648.

[9] SUBHASH, G., LOUKUS, J.E., PANDIT, S.M. (2002). Application of data dependent systems approach for evaluation of fracture modes during a single-grit scratching. In: Mechanics of Materials, Vol. 34, No.1, pp. 25-42. Elsevier. Netherlands. ISSN 0167-6636.

[10] KUNDRAK, J., PALMAI, Z. (2019). The change of tool life in a wide range of cutting speeds in hard turning. In: Manufacturing Technology, Vol. 19, No.2, pp. 254-260. Elsevier. Netherlands. ISSN 1213-2489.

[11] DING, T., ZHANG, S., WANG, Y., ZHU, X. (2010). Empirical models and optimal cutting parameters for cutting forces and surface roughness in hard milling of AISI H13 steel. In: International Journal of Advanced Manufacturing Technology, Vol. 51, pp. 45-55. Springer. Germany. ISSN 0268-3768.

[12] WU, H., HUANG, H., XU, X. (2018). The influence of crystallographic orientation on wear characteristics during single abrasive diamond grit scratching on sapphire. In: Industrial Lubrication and Tribology, Vol. 70, No.8, pp. 14141421. Emerald. England. ISSN 0036-8792.

[13] ASLAN, D., BUDAK, E. (2014). Semi-analytical Force Model for Grinding Operations. In: Procedia CIRP, Vol. 14, pp. 7-12. Elsevier. Netherlands. ISSN 2212-8271. 